AUTHOR:

Hannah R. Simon ${ }^{1,2}$

\title{
Understanding the polarisation of environmental and social activism in South Africa
}

Heralded as the decade of social awareness, the start of the 21 st century has brought with it a growing cognisance of what is good and right. Through time, the world has birthed different schools of justice, which have all added their flavours to the hypothetical cocktail of human well-being. Two of these schools - social justice and environmental justice - have attracted the most attention.

The United Kingdom's Department of Forestry has deemed social justice the 'shar[ing] of social, environmental and economic benefits' and environmental justice the 'distribution of environmental benefits'. When either of these justices are not met, waves of resistance - so-called social and environmental activism, respectively - invariably arise. Social activism effectively caters directly to the needs of people, whilst environmental activism prioritises the state of the environment.

\section{CORRESPONDENCE TO:}

Hannah Simon

EMAIL:

hannah.r.simon@gmail.com

\section{KEYWORDS:}

conservation; social activism; environmental justice; poverty; green culture

\section{HOW TO CITE:}

Simon HR. Understanding the polarisation of environmental and social activism in South Africa. S Afr J Sci. 2016;112(11/12), Art. \#a0180, 2 pages. http:// dx.doi.org/10.17159/sajs.2016/ a0180

Theoretically, a country should be able to protect a society along with its environment. In fact, in many countries, governments, citizens and policymakers have been able to do just that: for example, Bolivia's 'Law of Mother Earth' or Stuttgart's 'Cool City Framework'. ${ }^{2}$ Hence, in many cases globally, the two are not seen as separate entities. However, attempts to rectify South Africa's turbulent socio-economic past have resulted in social justice being wedged at the forefront of post-apartheid plans and policies. Consequently, saving the environment has fallen subsidiary to some of the more pressing social issues - such as housing, cultural expression and employment - in South Africa. The result of this sidelining has been the polarisation of environmental and social activism, with the subsequent prioritisation of the latter. Here are three key reasons why this phenomenon may be evident globally, and may be especially true in South Africa.

\section{Swift social change versus steady environmental change}

In many ways, environmental activism and social justice cannot be equated because they occur over very different scales in space and time. Drastic and definite changes in global climate operate over hundreds to millions of years; the life cycle of a local socio-economic issue, however, can complete within a single year. For example, if we culled carbon dioxide emissions today, it is likely, although not certain, to take millennia for it to leave the atmosphere as gas and calcify to rock. In the past, social transformation in South Africa has also taken some time. Tracing the history of colonialism and white dominance from the 1800s all the way to the white/non-white economic dichotomy today helps to illustrate this. Irrespective of the numerous post-apartheid policy changes, over 20 years into democracy, the average white person still earns approximately six times as much as a person of colour. ${ }^{3}$

However, more and more evidence is suggesting that social reform operates, on average, over much shorter time frames than environmental intervention can. For example, within a single month in late 2015, South Africa witnessed one of its biggest student uprisings since Soweto 1976. The \#FeesMustFall and \#RhodesMustFall movements, active across most of the country's universities, made socio-economic demands that were recognised and addressed almost immediately.

As we broaden our scope to encompass larger and longer spatio-temporal scales - so characteristic of most environmental issues - we lose more and more certainty of future projections. In light of this, and of the poverty so characteristic of South African society, how can one reasonably expect the country's urban poor to curtail electricity usage today, for example, when the long-term future of earth's energy stocks are so unreliable? Should we be modifying cause without certainty of effect in a country in which resource demand is far exceeding supply? Hence, environmental activism is often not a priority in South Africa because it requires an invaluable investment of patience and risk before actual change can be seen. In a political economy such as South Africa's, economic desperation does not allow for risk taking and money wasting. Support for social activism, on the other hand, has grown because over reasonable time frames an issue can often be identified and solved, with some degree of certainty.

\section{Obscure environmental issues versus tangible social solutions}

Environmental activism prioritises something that is relatively esoteric whilst social justice offers tangible solutions. Worldwide, climate change scientists sometimes fail at gaining support because their numbers and reasoning cannot be understood by the general public. Still, scientists often argue that their work is accessible, explaining simply that, for example, sea levels will rise along with global surface temperatures. The Intergovernmental Panel on Climate Change has estimated that at worst-case scenario global surface temperatures will rise by approximately $4{ }^{\circ} \mathrm{C}$ by $2100 .{ }^{4}$ This is simple enough, but how well does it represent the lived experience of the average South African? To what extent does it help us to understand how climate change will actually affect us in our or in our children's lifetimes? If we cannot wholly understand the potential repercussions of global change, then it is unlikely that we will garner enough support to mitigate them.

In some respects, social issues such as racism and gender inequality have also been heralded as extremely esoteric. Based almost entirely on personal experience, many social issues cannot be reduced to neat mathematical formulae and solved. Interestingly, these same issues have most often been accepted as direct, accessible and solvable. For example, at the University of Cape Town, tangible 'solutions' - such as the renaming of buildings, the eradication of fee increases and the removal of colonial memorabilia - that directly impacted social well-being have, especially since late 2015 , been implemented. Such solutions have provided concrete, quantitative and relatively simple evidence that socio-economic problems can, in theory, be compensated for. Whether or not 
these solutions have been effective in executing true change is another topic of contention. Environmental problems, on the other hand, require rigorous data analyses before any steps can be taken to curb global change. This explains why it is so difficult to provide viable solutions that can benefit both people and the environment at the same time. Further, it emphasises why social change is often prioritised over environmental intervention in South Africa.

\section{A green culture versus a cultural tradition}

Environmental justice and social activism can also be at odds in South Africa because of a clash in world views. Aspects of South African society present a battle between culture and the environment, whereby many cultural practices in this country are extremely environmentally unfriendly. Rearing livestock, for example, has been heralded as one of the largest sources of greenhouse gases, the most prominent water pollutant and the key driver of biodiversity loss. It has been estimated that approximately $10000 \mathrm{~L}$ of water is required to produce a single 450-g meat patty. ${ }^{5}$ With this in mind, environmentalists worldwide are likely to encourage a shift from meat-eating towards a plant-based diet.

However, South Africa's cultural and culinary history is likely to stall or to even resist this shift. From the beginning of the Upper Palaeolithic, San hunter-gatherers have been killing and eating large game. ${ }^{6}$ This practice is deeply embedded in South African culture and, although it has been deemed environmentally sustainable, it represents the mechanisms on which modern meat production and consumption - practices that are invariably not sustainable - are based. Today, 24 September has been set aside annually as a public holiday (National Heritage Day) and is devoted to celebrating our heritage through the making of a braai. National Heritage Day has been labelled a 'noble cause that will contribute to strengthening South Africa as a nation through social cohesion'? This is representative of a bigger meat-eating creed that characterises South African society, across cultures, and without proper consideration of the potential environmental impacts.

In light of the turbulent socio-economic past of this country, social cohesion and nation-building is indeed an urgent issue that needs addressing, but unfortunately is often pursued at the expense of the environment. Conservationists have delved deeper into the environmentsociety clash by exploring other cultural practices that impede the health of South Africa's ecosystems. One such example is through the utilisation of leopard skins in traditional religious rituals conducted by members of the Shembe Church, a hybrid of Zulu and Old Testament Christian religions. During the 1970s, about 50000 leopards were killed annually to sustain these practices. ${ }^{8}$ In theory, the leopard skin trade could, according to environmentalists, quite easily be obliterated. However, who decides whether biodiversity or an entire cultural practice should be jeopardised? Such a clash in world views makes it difficult to simultaneously balance the needs of the environment with that of South African society.
Amongst others, three key variables - time scale, tangibility and culture - illustrate the contrasts between environmental justice and social activism. Debates continue as to whether these variables can be dealt with together. On one hand, a nexus of governance, environment and people can and should be formed, ensuring that each issue is tackled relative to the other. Scientists Gordon McGranahan and David Satterthwaite have coined this phenomenon 'bridging the green and brown agendas'9. However, South Africa's case is complicated. This country has urgent socio-economic matters which need to be addressed before finding too many causes and fixing none. Given the current socioeconomic standing of this country, environmental cooperation is unlikely to ever be achieved until people have been granted true and democratic social justice.

The opinions expressed herein do not necessarily reflect the views of the University of Cape Town.

\section{References}

1. Lucas K, Walker G, Eames M, Fay H, Poustie M. Environment and social justice: Rapid research and evidence review. London: Policy Studies Institute; 2004.

2. Rehan R. Cool city as a sustainable example of heat island management case study of the coolest city in the world. HBRC J. 2014;12(2):191-204. http:// dx.doi.org/10.1016/j.hbrcj.2014.10.002

3. Wilkinson K. Race, poverty and inequality: Black first land claims factchecked. Africa Check. 2015 27; FACTSHEET. Available online from: https:// africacheck.org/reports/race-poverty-and-inequality-black-first-land-firstclaims-fact-checked/

4. Intergovernmental Panel on Climate Change (IPCC). Final draft of the special report on emission scenarios. Technical Support Unit of IPCC Working Group III. Bilthoven: Netherlands Environmental Assessment Agency; 2000.

5. Oppenlander RA. Food choice and sustainability: Why buying local, eating less meat and taking baby steps won't work. Minneapolis, MN: Langdon Street Press; 2013.

6. Barnard A. Hunters and herders of southern Africa: A comparative ethnography of the Khoisan peoples. Cambridge: Cambridge University Press; 1992. http:// dx.doi.org/10.1017/CB09781139166508

7. Scannell J. National Braai Day: Our mission [homepage on the Internet]. c2007 [cited 2016 Sep 01]. Available from: http://braai.com/national-braaiday-mission/

8. Ramsay S. \#ShockWildlifeTruths: Will the Zulu traditional dress wipe out the SA leopard? News24. 2016 February 29; Traveller24 [cited 2016 Sep 01]. Available from: http://traveller24.news24.com/Explore/Green/ shockwildlifetruths-will-the-zulu-skin-trade-wipe-out-the-leopard-20160229

9. McGranahan G, Satterthwaite D. Environmental health or ecological sustainability: Reconciling the brown and green agendas in urban development. In: Pugh C, editor. Sustainable cities in developing countries. London: Earthscan; 2013. p. 73-90. 